\title{
EFFECT OF AL ADDITION ON MICROSTRUCTURE OF AZ91D
}

\author{
Utsavi Joshi ${ }^{1}$, Nadendla Hari Babu ${ }^{2}$ \\ ${ }^{1,2}$ BCAST (Brunel Centre for Advanced Solidification technology), Brunel University, Uxbridge, Middlesex UB8 3PH, UK
}

Keywords: AZ91D Mg alloy, Grain refinement, Al-B master alloy

\begin{abstract}
Casting is a net shape or near net shape forming process so workhardening will not be applicable for improving properties of magnesium cast alloys. Grain refinement, solid-solution strengthening, precipitation hardening and specially designed heat treatment are the techniques used to enhance the properties of these alloys. This research focusses on grain refinement of magnesium alloy AZ91D, which is a widely used commercial cast alloy. Recently, Al-B based master alloys have shown potential in grain refining AZ91D. A comparative study of the grain refinement of AZ91D by addition of $0.02 \mathrm{wt} \% \mathrm{~B}, 0.04 \mathrm{wt} \% \mathrm{~B}$, $0.1 \mathrm{wt} \% \mathrm{~B}, 0.5 \mathrm{wt} \% \mathrm{~B}$ and $1.0 \mathrm{wt} \% \mathrm{~B}$ of $\mathrm{Al}-5 \mathrm{~B}$ master alloy and equivalent amount of solute element aluminium is described in this paper. Hardness profile of AZ91D alloyed with boron and aluminium is compared.
\end{abstract}

\section{Introduction}

Magnesium alloys have shown great potential in structural applications due to their many appreciated properties. The efforts by automotive sector to reduce fuel consumption and vehicle emissions have increased the demand for light weight magnesium alloys as a structural material. Apart from automotive sector, magnesium alloys have also attracted application in electric and aerospace industries. Therefore, the associated investigations are of high interest to researchers and designers.

AZ91D is the most widely used commercial magnesium alloy containing aluminium but its mechanical properties are relatively low, which cannot meet the requirements of certain applications [1]. Grain refinement can improve the mechanical properties of an alloy which involves the formation of fine equiaxed grains at the expense of dendrites. It also offers other advantages such as reduction in hot tearing susceptibility and improved corrosion resistance. Various methods used for grain refinement include addition of trace elements or master alloy, ultrasonic treatment or electromagnetic field, introduction of fine gas bubbles in the melt and applying coatings to mould surface. Inoculation of melt is the most commonly used method for grain refinement of $\mathrm{Mg}$ alloys as $\mathrm{Mg}$ has a hexagonal close packed (HCP) structure and it is difficult to decrease the grain size through thermomechanical processing due to limited slip systems. Many commercial alloy systems such as the aluminium bearing magnesium alloys (AZ91, AZ31 and AM50) do not have any established grain refiner that is cost-effective and reliable. Numerous potential additions based on carbon, calcium, boron and strontium have been examined by researchers for grain refinement on AZ91 alloy [2, 3, 4, 5, 6, 7]. Carbon based additions have shown significant refinement but it causes environmental pollution while boron addition is maintained longer and is considered more feasible [8]. The effect of aluminium content on microstructure of $\mathrm{Mg}-\mathrm{Al}$ alloys has been studied by Dargusch et al [9] and the effect of boron addition on grain refinement of AZ91 alloy has been studied by Suresh et al [5]. In this research, we do a comparative study of addition of boron based master alloy $\mathrm{Al}-5 \mathrm{~B}$ and equivalent solute addition in form of $\mathrm{Al}$ to the grain refinement of AZ91D alloy.

\section{Experimental Procedure}

The chemical composition of AZ91D alloy considered for this study is $8.95 \% \mathrm{Al}, 0.72 \% \mathrm{Zn}, 0.19 \% \mathrm{Mn}, 0.039 \% \mathrm{Si},<0.001 \% \mathrm{Fe}$, $0.001 \% \mathrm{Cu},<0.001 \% \mathrm{Ni}, 7 \mathrm{ppm} \mathrm{Be}$ and remaining $\mathrm{Mg}$. For the casting experiments, the alloy is initially melted in a conventional furnace lined with steel mould. When the temperature of the melt reaches $720^{\circ} \mathrm{C}$, the melt is held at this temperature for at least an hour before casting the reference sample or addition of grain refiner in form of master alloy. To obtain reference sample, the melt is cooled to $710 \pm 2^{\circ} \mathrm{C}$ and cast in a preheated $\left(250^{\circ} \mathrm{C}\right)$ steel cylindrical mould with inner dimensions of $30 \mathrm{~mm}$ diameter and $120 \mathrm{~mm}$ height. In the case of addition of grain refiner, the master alloy Al-5B is added to the melt and left for 20 minutes before casting at $710 \pm 2^{\circ} \mathrm{C}$. Intermittent stirring is carried out twice after master alloy addition for its dissolution and homogeneous distribution within the melt. Cover gas of a mixture of sulphurhexafluoride and nitrogen is used during melting and holding of the melt. No flux is used during this experiment. For microstructural analysis, cylindrical samples of dimension $30 \mathrm{~mm}$ diameter and $20 \mathrm{~mm}$ height were machined out of these castings. These samples are ground and polished using standard procedures for optical microscopy and colour etched using a mixture of $5 \mathrm{ml}$ acetic acid; $10 \mathrm{ml}$ distilled water; $100 \mathrm{ml}$ ethanol and $6 \mathrm{gm}$ picric acid known as the acetic- picral reagent. The linear intercept method was used to measure the grain size using a Zeiss Axioskop2 MAT optical microscope.

\section{Results and Discussion}

\section{Effect of Boron Addition on Grain Refinement}

The microstructures of AZ91D with and without boron addition are shown in Figure 1. The average grain size of AZ91D alloy without any addition was about $422 \pm 35 \mu \mathrm{m}$. Addition of boron alone in the form of powder was observed to give no change in the grain size of AZ91D alloy since the powder did not submerge and remained dispersed on the surface of melt. Boron was therefore introduced in the form of Al-5B master alloy.

Increase in boron addition from $0.02 \mathrm{wt} \%$ to $0.1 \mathrm{wt} \%$ showed very little grain refinement in AZ91D alloy. But $1.0 \% \mathrm{~B}$ addition in form of Al-5B master alloy decreased the grain size significantly from $422 \pm 35 \mu \mathrm{m}$ to around $67 \pm 5 \mu \mathrm{m}$. This is attributed to the solute effect of $\mathrm{Al}$ since boron is added in the form of $\mathrm{Al}-5 \mathrm{~B}$ master alloy. AZ91D alloy when added with $1 \% \mathrm{~B}$ in form of $\mathrm{Al}-$ 5B master alloy did not reveal a clear polarized image. The aceticpicral reagent was used for etching these samples and since the magnesium alloy AZ91D has now changed to a different composition with very high $\mathrm{Al}$ content, the etchant did not reveal a clear polarized image. 


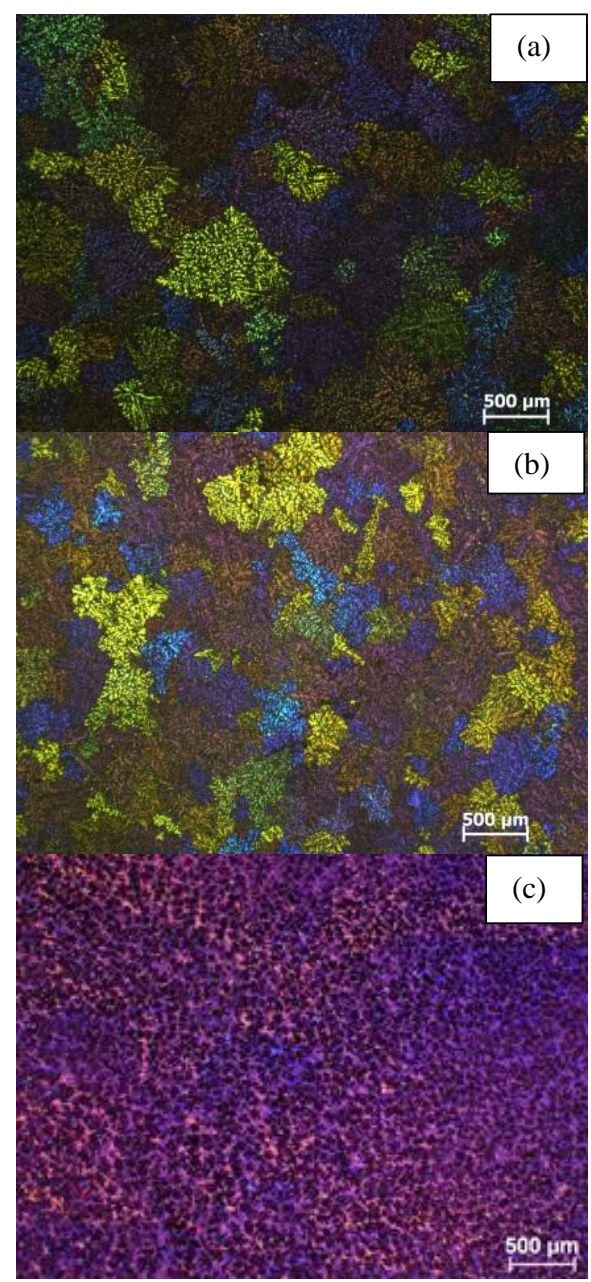

Figure 1: Microstructures of AZ91D with (a) $0 \% \mathrm{~B}$ (b) $0.04 \% \mathrm{~B}$ and $0.76 \% \mathrm{Al}$ and $(\mathrm{c}) 1.0 \% \mathrm{~B}$ and $19.0 \% \mathrm{Al}$ in the form of $\mathrm{Al}-5 \mathrm{~B}$ master alloy

\section{Effect of Al Addition on Grain Refinement}

\begin{tabular}{|c|c|}
\hline $\begin{array}{c}\text { Boron in } \\
\text { Al-5B } \\
\text { (wt\%) }\end{array}$ & $\begin{array}{c}\text { Equivalent } \\
\text { Al in Al-5B } \\
\text { (wt\%) }\end{array}$ \\
\hline 0.02 & 0.38 \\
\hline 0.04 & 0.76 \\
\hline 0.10 & 1.90 \\
\hline 0.50 & 9.50 \\
\hline 1.00 & 19.00 \\
\hline
\end{tabular}

Table 1: Boron addition levels in form of Al-5B master alloy and the corresponding $\mathrm{Al}$ content in the master allov.

To identify the contribution of $\mathrm{Al}$ in $\mathrm{Al}-5 \mathrm{~B}$ to the grain refinement of AZ91D alloy, in a separate experiment, a series of AZ91D alloys were cast after adding various amounts of $\mathrm{Al}$. The $\mathrm{Al}$ addition levels as shown in $2^{\text {nd }}$ column of Table 1 , represents $\mathrm{Al}$ content in Al-5B master alloy for boron levels of $0.02 \mathrm{wt} \%$, $0.04 \mathrm{wt} \%, 0.1 \mathrm{wt} \%, 0.5 \mathrm{wt} \%$ and $1.0 \mathrm{wt} \%$. The micrographs for $\mathrm{Al}$ added AZ91D alloys are shown in Figure 2.

Figure 2 indicate that increase in $\mathrm{Al}$ additions from $0.38 \%$ to $19.0 \%$ has similar effect on average grain size of AZ91D alloy as observed in Figure 1, where equivalent boron $(0.02 \%$ to $1.00 \%)$ is added in the form of Al-5B master alloy.

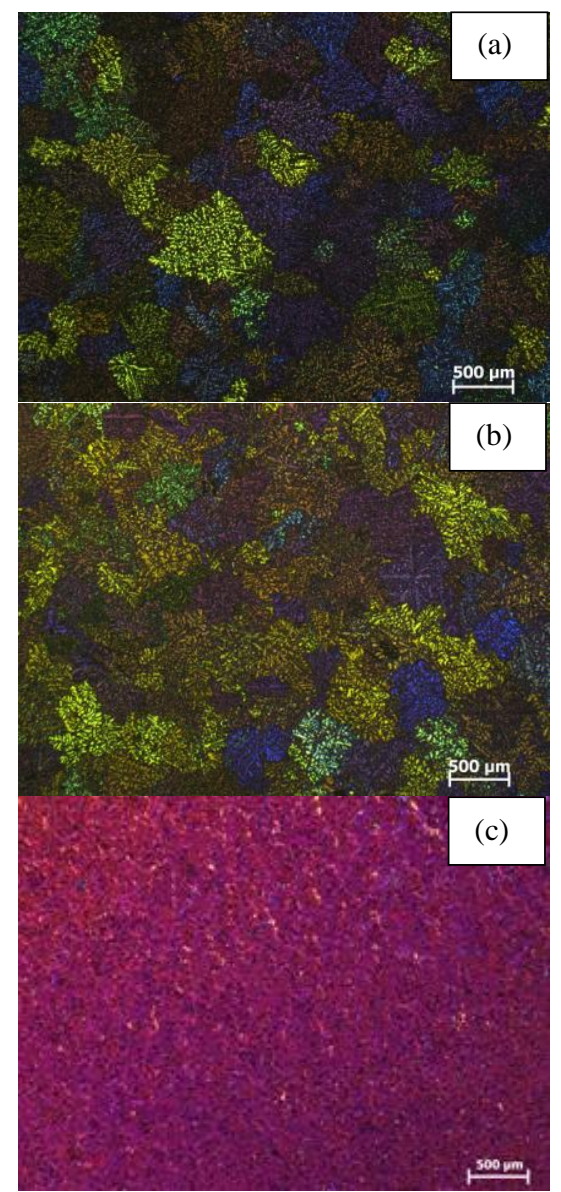

Figure 2: Microstructures of AZ91D with (a) 0\%Al (b) $0.76 \% \mathrm{Al}$ and (c) $19.0 \% \mathrm{Al}$

Any refinement in grain structure of AZ91D observed due to $\mathrm{Al}$ additions could be attributed to growth restriction factor (GRF) theory. Previous studies on $\mathrm{Al}$ alloys and $\mathrm{Mg}$ alloys have explained the role of solute in controlling the growth of nucleated grains and subsequent nucleation through this theory $[10,11,12$, 13 ]. The grain growth will be restricted as the diffusion of solute Al occurs slowly due to constitutional undercooling ahead of the advancing solid/liquid interface. Addition of boron in form of Al5B master alloy and equivalent aluminium has similar effect on average grain size of AZ91D. Figure 3 suggests that $\mathrm{Al}$ contribution could be significant to the grain refinement in AZ91D when Al-5B master alloy is added to a magnesium alloy. 

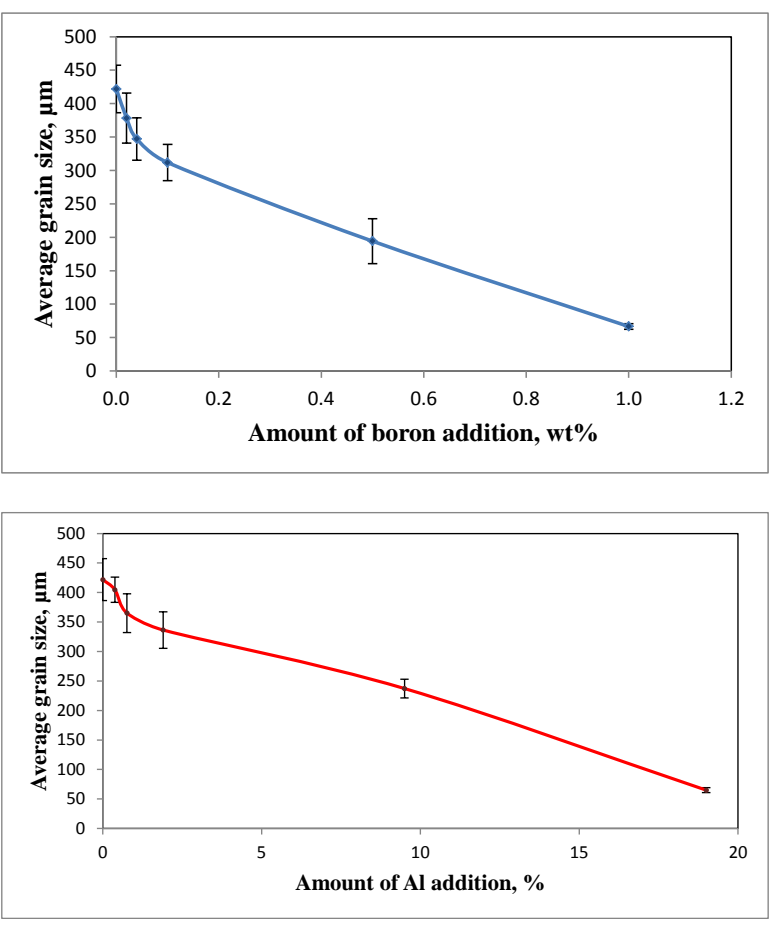

Figure 3: Relation between average grain size of AZ91D and (a) boron addition in form of $\mathrm{Al}-5 \mathrm{~B}$ and (b) $\mathrm{Al}$ addition
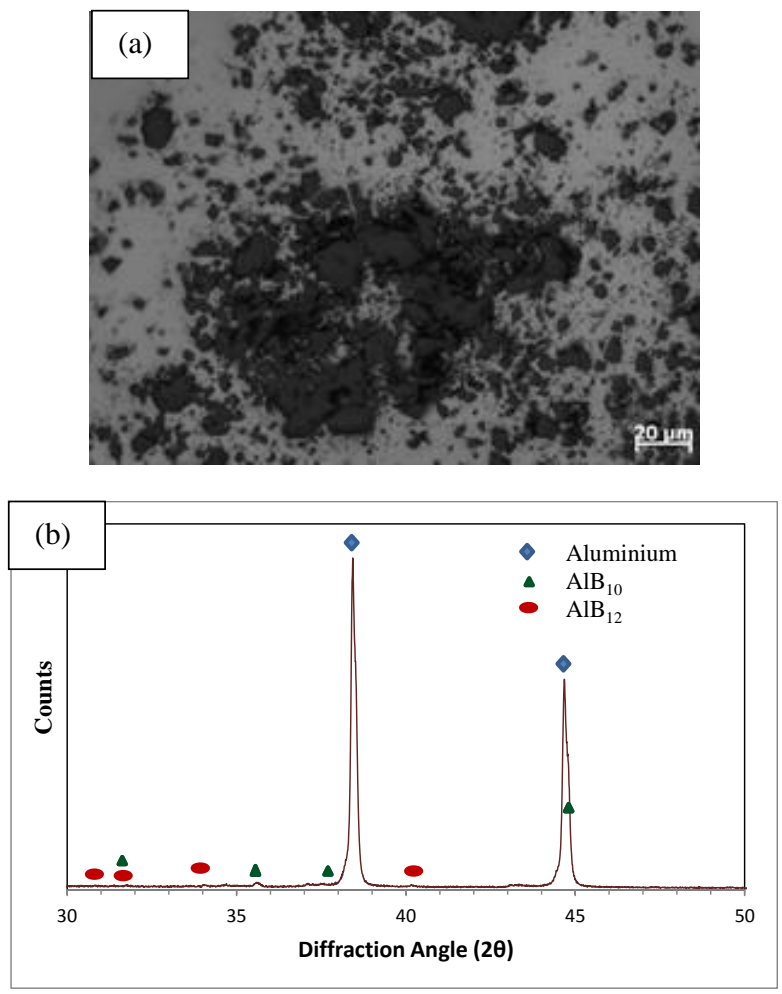

Figure 4: (a) Optical micrographs of Al-5B master alloy (b) XRD pattern of $\mathrm{Al}-5 \mathrm{~B}$ master alloy
The microstructure of Al-5B alloy is as shown in Figure 4 (a). The particles were identified as $\mathrm{AlB}_{12}$ and $\mathrm{AlB}_{10}$ by $\mathrm{X}$-ray diffraction analysis. As shown in Figure 4(b) there are no clear $\mathrm{AlB}_{2}$ peaks being resolved, an indication of minor amount of $\mathrm{AlB}_{2}$ in this master alloy. The heat accumulation owing to highly exothermic salt reaction could be responsible for formation of $\mathrm{AlB}_{12}$ during the production of Al-5B master alloy [14].
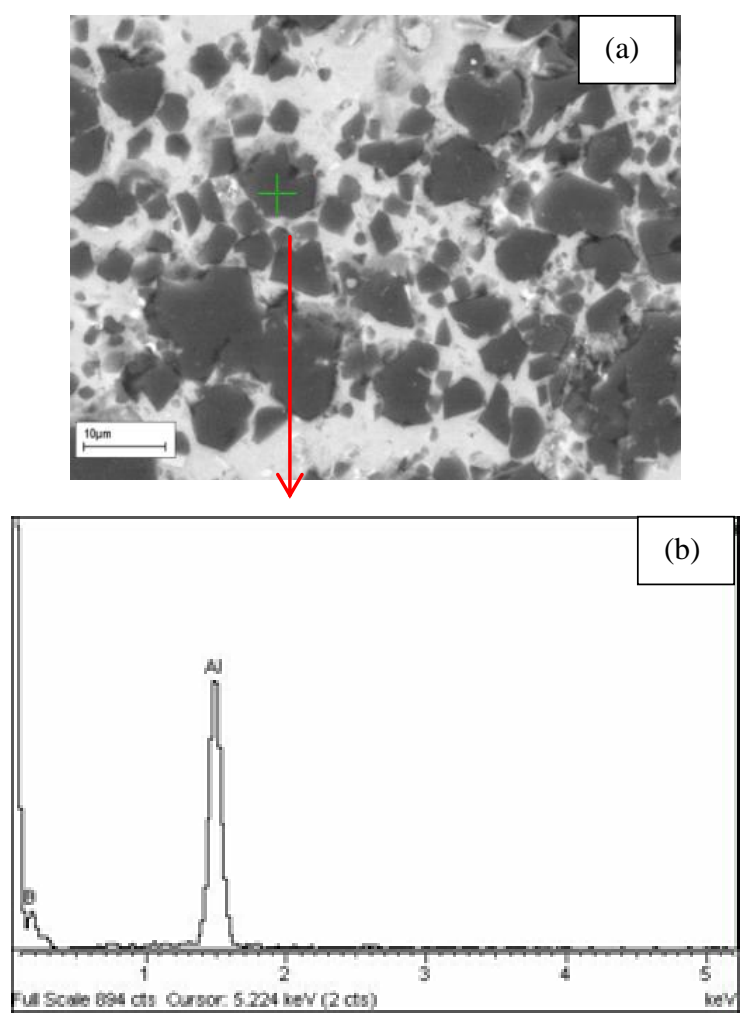

Figure 5: (a) SEM image of Al-5B master alloy revealing Boride particles, and (b) The EDS spectrum of boride particle

Figure 5 shows SEM image of the Al-5B master alloy and the EDS spectrum of the observed boride particles. Smaller numbers of backscattered electrons are generated by boron-rich particles as compared to aluminium due to boron being a lower atomic number element, resulting in dark boride particles surrounded by bright aluminium matrix. These boride particles were seen as clusters in the aluminium matrix. The SEM image did not reveal any clear hexagonal platelets while the irregular polyhedral particles could be attributed to the presence of $\mathrm{AlB}_{12}$ and $\mathrm{AlB}_{10}$ phases. $\mathrm{AlB}_{10}$ have been reported to be metastable phase however, the presence of impurities in Al-5B master alloy could be attributed to its stability.

Previous studies have reported that manganese plays an important role in dispersing the Al-B compounds which could act as potential nucleating sites [8]. But results in this study appeared to the contrary as despite $0.19 \mathrm{wt} \% \mathrm{Mn}$ content in the magnesium alloy there was little effect on grain refinement except at very high concentrations of $\mathrm{Al}$ content when a completely new alloy is formed and the base alloy is no more AZ91D. 


\section{Effect of Boron and Equivalent Al Addition on Hardness}

The hardness values of the samples were measured using INDENTEC hardness tester. Each hardness value reported is an average of 12 measurements.

As show in Figure 6, the micro hardness of the as-cast AZ91D alloy increased from $67 \mathrm{HV} 0.3$ to $136 \mathrm{HV} 0.3$ at $1.0 \mathrm{wt} \% \mathrm{~B}$ addition in form of $\mathrm{Al}-5 \mathrm{~B}$. The hardness profile on equivalent $\mathrm{Al}$ addition is also in the similar range. Similar average grain size obtained on addition of boron and equivalent $\mathrm{Al}$ supports the hardness profiles obtained in each case.

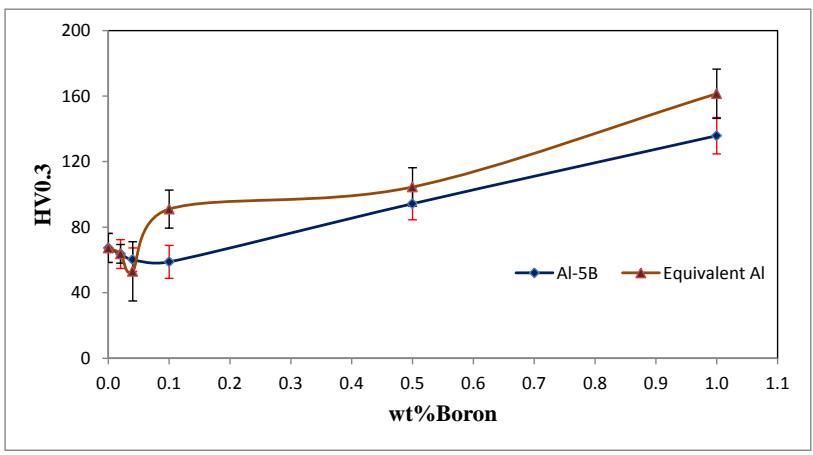

Figure 6: Effect on hardness value with boron and equivalent $\mathrm{Al}$ addition

The boride particles could impede the movement of the dislocations very effectively and contribute to the overall strength. Also, it is widely accepted that $\mathrm{Mg}$ alloys usually have a much larger Hall-Petch coefficient compared to $\mathrm{Al}$ alloys leading to a higher efficiency of strengthening through grain refinement.

\section{Summary}

The addition of Al-5B master alloy is observed to decrease the grain size of AZ91D alloy. Al addition to AZ91D is also observed to refine the grain size to the similar magnitude. The refinement with $\mathrm{Al}-5 \mathrm{~B}$ addition could therefore be primarily associated with $\mathrm{Al}$ solute rather than $\mathrm{AlB}_{10}$ or $\mathrm{AlB}_{12}$ acting as inoculants.

The hardness profile is similar for both $\mathrm{Al}-5 \mathrm{~B}$ master alloy and $\mathrm{Al}$ additions to $\mathrm{AZ91D}$, which also suggests that the $\mathrm{Al}$ solute plays a major role in grain refinement rather than $\mathrm{AlB}_{12} / \mathrm{AlB}_{10}$ phases.

\section{References}

1. D. Eliezer, E. Aghion, F.H. Fross, "Magnesium Science, technology and applications", Journal of Advanced Performance Materials, 5 (1998), 201-212

2. Chen et al., "Grain refinement of AZ91D magnesium alloy by SiC", Journal of Alloys and Compounds, 496 (1-2) (2010), 218-225

3. Liu et al., "Effect of Mg-TiB2 master alloy on the grain refinement of AZ91D magnesium alloy", Journal of Alloys and compounds, 487 (1-2) (2009), 202-205
4. Chen et al., "Grain refinement of AZ91D magnesium alloy by Al-Ti-B master alloy and its effect on mechanical properties”, Materials \& Design, 34 (2012), 637-648

5. Suresh et al., "Influence of boron addition on the grain refinement and mechanical peoperties of AZ91 Mg alloy", Materials Science and Engineering A, 525 (2009) 207-210

6. L Piejie, T. Bin and E.G. Kandalova, "Microstructure and properties of AZ91D alloy with Ca additions", Materials Letters 59 (6) (2005), 671-675

7. Kim,Y., Yim,C., and You,B., "Grain refining mechanism in Mg-Al base alloys with carbon addition", Scripta Materialia, 57 (8) (2007), 691-694

8. Nishino et al., "Grain refinement of magnesium casting alloys by boron addition", In: Proceedings of the International Conference on Magnesium Alloys and their Applications, September 2000. Germany: Wiley, 59-64

9. Dargusch et al., "The effect of aluminium content on the mechanical properties and microstructure of die cast binary magnesium-aluminium alloys", Materials Transactions, 47 (4) (2006), 977-982

10. L. Backerud and M. Johnsson: in Light Metals, W. Hale, ed.,TMS, Warrendale, PA, 1996, 679-85

11. I. Maxwell and A. Hellawell, "A simple model for grain refinement during solidification", Acta Metallurgica, 23 (1975), 229-37

12. Y.C. Lee, A.K. Dahle, D.H. Stjohn, "The role of solute in grain refinement of magnesium", Metallurgical and Materials Transaction, 31A (11) (2000) 2895-2906.

13. Cheng et al., "Effect of $\mathrm{Sr}$ addition on the grain refinement of AZ31 magnesium alloys", Progress in Natural Science: Materials International, 23 (1) (2013), 7-12

14. Wang, $\mathrm{X}$, "The formation of $\mathrm{AlB}_{2}$ in an $\mathrm{Al}-\mathrm{B}$ master alloy", Journal of Alloys and Compounds, 403 (2005) 283-287 